\title{
O legado freiriano para uma Educação Física escolar contra-hegemônica
}

\author{
The freiriano legacy for physical education at schools against hegemonics
}

Legado freiriano para una Educación Física escolar contra hegemónica

\begin{abstract}
Alessandra Andrea Monteiro - Universidade Ibirapuera | Faculdade de Educação Física / Coordenadora Pedagógica | São Paulo | SP | Brasil. E-mail: alemonteirobr@gmail.com |

Resumo: O artigo, de caráter ensaístico, apresenta a reflexão sobre a contribuição da obra de Paulo Freire para a área da Educação Física escolar e sua importância para a consolidação de práticas contra-hegemônicas. À luz das ideias freirianas, em convergência com as teorias críticas e pós-críticas do currículo, dá ênfase aos conceitos do diálogo, da ética, da amorosidade, da diretividade, da reflexão e da rigorosidade, elementos basilares para a ação dos professores nas instituições escolares. O objetivo deste ensaio é contribuir para o debate acerca da prática pedagógica progressista da Educação Física escolar, não apenas sob a égide do ideário freiriano, mas em aproximação com o aporte teórico que orienta o trabalho docente democrático e emancipatório no cotidiano escolar.
\end{abstract}

Palavras-chave: Educação física. Práticas pedagógicas. Paulo Freire.

Abstract: The essay, of an essayistic nature, presents a reflection on the contribution of Paulo Freire's work to the field of Physical Education at schools and its importance for the consolidation of counter-hegemonic practices. In the light of Freire's ideas, in convergence with the critical and post-critical theories of the curriculum, emphasizes the concepts of dialogue, ethics, love, directness, reflection and rigor, basic elements for the action of teachers in educational institutions. The purpose of this essay is to contribute to the debate about the progressive pedagogical practice of Physical Education at schools, not only under the aegis of Freires's ideas, but in approximation with the theoretical contribution that guides democratic and emancipatory teaching in the school routine.

Keywords: Physical education. Pedagogical practices. Paulo Freire. 
Resumen: El artículo, de carácter ensayístico, presenta una meditación sobre el aporte del trabajo de Paulo Freire al campo de la Educación Física en la Escuela y su importancia para la consolidación de las prácticas contrahegemónicas. A la luz de las ideas freirianas, en convergencia con las teorías críticas y post críticas de Currículo, se da énfasis a los conceptos de diálogo, ética, amor, franqueza, reflexión y rigor, elementos básicos para la acción de los docentes en las instituciones escolares. El propósito de este ensayo es contribuir al debate sobre la práctica pedagógica progresista de la Educación Física Escolar, no solo bajo el auspicio de las ideas freirianas, sino en acercamiento a la contribución teórica que guía el trabajo docente democrático y emancipador en la rutina escolar.

Palabras clave: Educación física. Prácticas pedagógicas. Paulo Freire. 


\section{Introdução}

Para a construção deste texto me afasto da condição de neutralidade proposta em um passado não muito distante nas produções sobre Educação e, ainda presente, nas discussões hodiernas sobre o tema. Aproximo minhas reflexões do esteio epistemológico das Ciências Humanas, refutando quaisquer outras formas de construir e fortificar meus pensamentos sobre o cotidiano da Educação Física escolar. Entendo o conhecimento científico como social e culturalmente construído, cuja interpretação e compreensão podem ser limitadas por uma série de experiências de vida e mundo. Contudo, as provocações que ora trago são pequenos fragmentos da tese de doutoramento desenvolvida junto a professores da rede pública municipal de São Paulo sobre as práticas pedagógicas da Educação Física escolar e Paulo Freire.

Não considero cabais as reflexões aqui trazidas, mas o preâmbulo de diálogos futuros com professoras e professores de Educação Física sobre nosso papel no cotidiano da escola. Paulo Freire não escreveu sobre corpo, corporeidade, movimento ou Educação Física. Todavia, o aporte teórico de suas reflexões acerca da Educação são um sustentáculo rigoroso e inexorável para a área e para a ambiciosa tarefa de professores irresignados com o panorama escolar, com a passividade de seus pares e com a falta de perspectiva de dias melhores.

$\mathrm{Na}$ atualidade, os sentimentos que se revelam em relação à escola são de desconfiança, desencanto e impotência frente aos problemas que emergem de seu cotidiano - indisciplina, fracasso escolar, reprovação, intolerância, violência, desrespeito entre tantos outros. O cenário brasileiro atravessa um período histórico e político conturbador e perigoso, no qual não apenas o papel da Educação é questionado, mas também as instituições escolarizadas e seus inúmeros atores, entre eles os professores de Educação Física. Monteiro (2018) alerta para a importância desta figura no intricado universo da escola, deslocando-o para o lado dos grupos marginalizados e assumindo seu papel de mediador do processo de ensino e de aprendizagem (GIROUX, 1995). Ao assumir esta posição, o educador exalta os conceitos freirianos de uma práxis pedagógica que difunde "[...] coerência entre o que se fala e o que se faz [...]” (MONTEIRO, 2018, p. 273).

Para pensar o espaçotempo do trabalho docente seleciono, inicialmente, dois desafios impostos aos professores que atuam "no chão da quadra" - a produção do conhecimento a partir de suas próprias ações pedagógicas e sua identificação como pesquisador-repletos de 
implicações éticas, políticas e pedagógicas. Estas inquietações passam longe do ineditismo esperado para as pesquisas acadêmicas, mas sob à luz da teoria freiriana, novas tintas se lançam sobre o tema.

Para Paulo Freire (2010), a figura do professor pesquisador não é algo descolado da realidade, nem uma qualidade desejada daqueles que atuam na escola. Ao contrário, a docência e a pesquisa são atributos indissociáveis ao professor na busca da excelência em suas práticas e sabe que a criticidade de e sobre suas ações “[...] envolve o movimento dinâmico, dialético, entre o fazer e o pensar sobre o fazer" (p. 38). Em que pese as diferentes concepções epistemológicas da prática pedagógica reflexiva, entendem que o professor deve assumir uma atitude etnográfica para alcançar a profundidade e a complexidade desejadas na análise e interpretação das manifestações corporais que compõem a aula de Educação Física escolar.

Outrossim, a prática pedagógica reflexiva se mostra como importante alternativa aos processos de ensino e de aprendizagem institucionalizados no cotidiano escolar que colocam a centralidade da produção e construção do conhecimento na figura do professor e desconsideram os saberes trazidos pelos demais sujeitos do processo educativo. Ademais, a educação, mesmo na informalidade, busca a inclusão dos indivíduos nas diferentes esferas da sociedade contemporânea e transcender formas de ensinar e aprender conservadoras e retrógradas. Ao optar por uma perspectiva reflexiva o professor mediador, alinhado aos saberes éticos, estéticos e políticos (FREIRE, 2010), revigora seu trabalho docente e coopera para o reconhecimento do componente curricular como essencial na formação cidadã, autônoma, crítica e emancipatória dos alunos durante todo o percurso da Educação Básica (FREIRE, 2016; NEIRA, 2016).

\section{Paulo Freire e Educação Física no cotidiano escolar}

No imaginário de muitas pessoas, os professores de Educação Física são aqueles que fazem, colocam "a mão na massa" e trabalham com o corpo em dimensões pouco valorizadas pela comunidade escolar. É bom que isso aconteça, afinal de contas algumas escolas ainda adotam práticas disciplinadoras para adequação do comportamento dos alunos, desconsiderando o corpo como partícipe fundamental dos processos de ensino e de aprendizagem (MONTEIRO, 2009). Contudo, as aulas não podem se resumir ao "fazer pelo fazer", à prática de repetições sem sentido ou significados para os educandos. Há que se planejar buscando a transcendência dos 
alunos, a conquista dos conhecimentos acadêmicos e científicos da Educação Física e sua inegável contribuição para a vida fora dos muros da escola.

É preciso uma mudança de comportamento para garantir aos docentes da área a mesma condição de status de seus pares, posto que a escola é, substancialmente, um local que privilegia a dimensão intelectual (inteligências linguística e lógico-matemática) dos processos educativos, em detrimento da dimensão corporal. A leitura e a escrita diárias se mostram importantes aliadas na luta dos professores para desvelarem a si próprios, para atribuírem sentido às suas ações pedagógicas e legitimarem a presença da Educação Física na escola. Não apenas como recreação, lazer ou para o condicionamento físico e esportivo dos alunos.

A “[...] 'cultura das aulas de Educação Física’ [...]” (VELOZO, 2009, p. 27), com sentido e significado para toda a comunidade escolar (pais, alunos, professores etc.), não garante ao componente o reconhecimento e a legitimidade na Educação Básica que gostaríamos, o mesmo acontece na Educação Superior. Essa cultura pauta-se, fundamental e desacertadamente, em uma visão biológica, cartesiana e fragmentada de ser humano. As aulas buscam a adequação dos corpos aos parâmetros considerados apropriados, educados, pela sociedade. Buscam até mesmo a especialização esportiva.

Ultrapassar a ideia da prática pela prática, contextualizar as manifestações corporais junto aos alunos, registrar as aulas, conquistas e fracassos - de alunos e professores - enxergar a escola e seus atores como campo de investigação e intervenção da Educação Física são o início do caminho para uma Educação progressista, democrática e emancipatória. Para isso, alinhar as práticas pedagógicas aos pressupostos das Ciências Humanas e Sociais traz contribuições que instigam a comunidade escolar e acadêmica a refletir e discutir sobre a Educação Física a partir de outros pressupostos. A estas conjecturas de caráter mais pedagógico, filosófico e humanista aproximo minhas reflexões sobre o legado freiriano para uma Educação Física contrahegemônica no cotidiano escolar.

A despeito das inúmeras pesquisas sobre a teoria freiriana (FREIRE, 1979; 1983a; 2001; 2010; 2015; 2016) para uma educação popular, emancipatória e libertadora e de defesa intransigente da escola pública, os professores de Educação Física não se apropriam destas ideias e tão pouco reconhecem seus elementos constitutivos em suas próprias práticas (MONTEIRO, 2018). A educação, como ato político, contribui para o processo de inclusão social e da 
construção da autonomia; e, a escola é o espaçotempo para a realização do inédito viável, da construção de uma sociedade mais justa.

Não tenho a ideia ingênua de que a escola é salvífica ou a resposta para todas as perguntas daqueles que vivem nesse autoritarismo contemporâneo. Todavia, ficam as inquietações para os docentes da área: Qual é o papel da Educação Física que se pretende progressista? O que se espera do corpo presenteausente na escola pública? Para responder a esses questionamentos buscamos o referencial de Paulo Freire e as relações tecidas com a Educação Física escolar.

A pedagogia freiriana legitima o diálogo, a ética, a amorosidade, a diretividade, a reflexão e a rigorosidade como elementos indissociáveis às práticas pedagógicas progressistas e democráticas, considerando-as dialógicas e dialéticas em uma relação de igualdade entre educador e educandos. Com vistas a compreender melhor as premissas do autor, algumas reflexões sobre os elementos mencionados se fazem necessárias.

\subsection{Diálogo}

No imaginário comum é a prática de transmitir algo a alguém, de comunicar ideias. No entanto, como elemento freiriano, é uma prática construída a partir do respeito com o outro em diferentes cenários. Pressupõe saber que a verdade em uma conversa não está somente consigo, mas na fala de outrem. É dialético e problematizador (FREIRE, 2016) com o propósito de olharmos e compreendermos nossa presença no mundo como um processo propositivo e esperançoso (STRECK; REDIN; ZITKOSKI, 2017).

Em uma Educação Física progressista é peremptório que o diálogo tenha início na seleção das manifestações corporais e dos conteúdos a serem ensinados, que privilegie a pergunta e suscite dúvidas aos alunos, levando-os a caminhar por avenidas de curiosidade epistemológica (MONTEIRO, 2018) e de compreensão crítica da realidade. Não há espaço para o autoritarismo nas práticas dialógicas. Ao contrário do que pensam muitos docentes - confundindo autoridade com autoritarismo - este não é um mal necessário para os processos de ensino e de aprendizagem. Não significa a ausência de conflitos, e, mesmo assim, o ato de ensinar é possível (FREIRE, 2015) como consequência de “[...] uma prática pedagógica democrática, aberta às diferenças e às divergências" (MONTEIRO, 2018, p. 46). 
O desafio, a ser incorporado pelos professores, é assentir que o aluno seja mais do que mero ouvinte, reprodutor de ideias, mas capaz de desenvolver "[...] a impaciência, a vivacidade, característica dos estados de procura, de invenção e reinvindicação” (FREIRE, 1967, p. 104). O diálogo verdadeiro também é a escuta honesta, respeitosa, amorosa e consciente daqueles que nunca tiveram oportunidade de fala. Exige um ouvinte paciente e atento, bem como o cuidado com as palavras no momento da discussão.

\section{2 Ética}

Elemento que percorre, implicitamente, toda a discussão de Paulo Freire sobre autoridade, emancipação e liberdade. Diz respeito às formas como nos relacionamos uns com os outros e com o mundo e, por consequência, nos apresenta a indissociabilidade entre ética e Educação. Parece óbvio, mas nem sempre o é (FREIRE, 1983b). No cotidiano escolar é um conceito pouco explorado, tanto por acadêmicos, quanto pelos professores no momento de planejar as intervenções pedagógicas.

A área da Educação Física carece de uma ética posicionada, explicitamente, ao lado de grupos minoritários, em práticas pedagógicas de justiça social, empatia, equidade e solidariedade. Os documentos curriculares oficiais, considerados fonte primária para a organização e elaboração destas ações, precisam se pautar em campos teóricos que permitam o diálogo de educandos e educadores com diferentes representações da cultura corporal, contrariando a tradição do componente curricular. Uma nova ética se estabelece a partir disso.

Não estabeleço - neste momento - as existentes diferenças conceituais entre ética e moral, mas entendo a primeira como condição inerente e indispensável à própria existência humana (FREIRE, 2010; 2015; 2016) e à Educação, sem a qual, o que se tem é deseducação.

\footnotetext{
Nunca me foi possível separar em dois momentos o ensino dos conteúdos da formação ética dos educandos. [...] O ensino dos conteúdos implica o testemunho ético do professor. A boniteza da prática docente se compõe do anseio vivo de competência do docente e dos discentes e de seu sonho ético.

Este é outro saber indispensável à prática docente. O saber da impossibilidade de desunir o ensino dos conteúdos da formação ética dos educandos (FREIRE, 2010, p. 94-95).
}

Esta não é uma discussão nova, mas, na escola, as atitudes éticas têm sido vistas com menos frequência em tempos de práticas individualistas e autoritárias. A racionalidade técnica do 
processo educativo reduz-se à aplicação de soluções de problemas, sem considerar as especificidades das relações entre os indivíduos e deles com o contexto escolar (FREITAS; COELHO, 2016). Na obra Professora sim, tia não: cartas a quem ousa ensinar, Freire (1997) já nos alertava para o sentido de comprometimento - ou ausência deste - do professor, pois “[...] a responsabilidade ética, política e profissional do ensinante lhe colocam o dever de se preparar, de se capacitar, de se formar antes mesmo de iniciar sua atividade docente" (p. 19).

\subsection{Amorosidade}

Para Paulo Freire somente o amor é capaz de prover educadores e educandos para a denúncia da realidade cotidiana e o anúncio de um mundo possível, em que os oprimidos possam expressar, livremente, seus pensamentos e sentimentos (MONTEIRO, 2018). É condição fundamental para homens e mulheres aprenderem, se colocarem e intervirem no mundo, com justiça social e de forma solidária, em um trabalho de muitas mãos. Os saberes docentes e discentes se interligam nessas relações de escuta, e, evidenciam a dialogicidade que incorpora o conceito de amorosidade aos diferentes elementos da teoria freiriana - a ética, a solidariedade etc.

Em tempos de incerteza, a escola assume a centralidade das discussões sobre o tipo de sociedade que desejamos e, por conseguinte, a Educação Física também. O trabalho docente não é apenas técnico, mas constituído por anseios, angústias, desejos, transcende a prática da atividade física e busca soterrar, indubitavelmente, a prática "rola bola" (TARDIF; LESSARD, 2011; MONTEIRO, 2018). Na sociedade contemporânea, amorosidade e diálogo são elementos determinantes para a criação de possibilidades e para mudanças de atitudes de professores e alunos. Andreola (2000), na carta-prefácio da obra Pedagogia da Indignação: cartas pedagógicas e outros escritos, traduz a amorosidade freiriana como a radicalidade de uma exigência ética:

\footnotetext{
Sem esquecer as perspectivas da inteligência, da razão, da corporeidade, da ética e da política, para a existência pessoal e coletiva, enfatizas também o papel das emoções, dos sentimentos, dos desejos, da vontade, da decisão, da resistência, da escolha, da curiosidade, da criatividade, da intuição, da esteticidade, da boniteza da vida, do mundo, do conhecimento. No que tange às emoções, reafirmas a amorosidade e a afetividade, como fatores básicos da vida humana e da educação (p. 13).
} 
O professor de Educação Física, ao assumir o amor pela docência, é capaz de renovar e inovar sua prática pedagógica. Ele seleciona temas culturais (CORAZZA, 1997) que dialoguem com os saberes dos educandos, muda estratégias e elabora instrumentos de avaliação coerentes com os objetivos de aprendizagem propostos para cada nível de ensino. Sua ação docente supera o pensamento linear, adota "[...] o pensamento complexo capaz de relacionar, enfrentar incertezas [...] valorizar o conhecimento do aluno, e reconhecer o homem como ser inacabado [...] pontos convergentes para uma pedagogia transformadora e amorosa" (ARRUDA et al., 2019, p. 253) e se humaniza.

\subsection{Diretividade}

Presente em toda ação docente, coerente com as concepções de educação, de mundo e de sociedade que se tem, esse conceito está entre as críticas mais ferozes e infundadas feitas à obra de Paulo Freire, ora com acusações de doutrinação ora imputando-o, justamente, a falta de diretividade. Essencial à prática de professores progressistas, entre eles os de Educação Física, para definição dos caminhos a serem trilhados durante o processo educacional.

Manifesta-se na escolha de estratégias que permitam aos alunos alcançar os diferentes conhecimentos, desde os cotidianos até os científicos, clássicos, artísticos, filosóficos desejados pelas instituições de educação escolarizada. Para esse fim, é preciso identificar, expressamente, quais conteúdos e temais culturais - no currículo para a Educação Física da cidade de São Paulo são chamados de inspiradores e de aprendizagens (SÃO PAULO, 2017) - serão trabalhados durante o percurso pedagógico da Educação Física escolar.

Para superar o paradigma biológico da área - excludente e elitista - é inescusável organizar o trabalho docente sob o esteio das reflexões críticas e democráticas acerca dos temas que constituem o universo da cultura corporal. Ensinar as práticas corporais pela perspectiva freiriana deve ser um exercício dialógico e democrático, pelo qual a autoridade do professor se constitui e se fortalece, “[...] superando autoritarismos e licenciosidades, considerados comportamentos disciplinadores e opressivos, muitas vezes despercebidos pelos professores" (MONTEIRO, 2018, p. 251). 


\section{5 Reflexão}

O caminho a ser trilhado pelos educadores progressistas passa, imperiosamente, por práticas de reflexão, na e sobre a ação docente e sobre as incontáveis manifestações da cultura corporal. É uma exigência incontornável das práticas progressistas, sem a qual a teoria não passa de blábláblá e a prática é apenas um fazer vazio, sem sentido ou significado (FREIRE, 2010). Este é o trabalho docente rigoroso, metódico e vigoroso esperado na perspectiva freiriana. Tardif (2011) anuncia que não se forma o professor reflexivo de uma hora para a outra, e que esse processo requer muito mais do que os saberes da formação profissional.

Segundo Neira e Nunes (2009), na década de 1990, a obra de Paulo Freire chega ao universo da Educação Física e inspira professoras e professores à construção de novas práticas pedagógicas; porém, em relação às investigações e análises dos conteúdos e temas da cultura corporal, sua teoria não trouxe avanços, já que as mesmas práticas corporais continuam em evidência nas quadras escolares. Destaco que a prática pedagógica democrática e progressista não renuncia aos conteúdos, uma vez que é epistêmica (MONTEIRO, 2018). Sua seleção dever ser realizada por professores e alunos, em um exercício democrático e crítico, de busca do conhecimento científico a partir do conhecimento advindo dos alunos, sem hierarquizá-los.

\subsection{Rigorosidade}

Paulo Freire $(2010 ; 2016)$ usa este elemento para explicar que a educação emancipatória não é sinônimo de educação sem autoridade, sem preocupação com estratégias, conteúdos e avaliação. É diferente de intransigência, bem como não caracteriza a preocupação do docente em cumprir todo o planejamento ou, no caso da Educação Física, não significa uma grande quantidade de práticas. Segundo Françoso e Neira (2014), para atestar sua competência, alguns professores decidem oferecer aos alunos muitas práticas corporais ao longo do ano letivo. Esse tipo de atitude não contribui para uma aula progressista, pois compromete outro elemento

essencial do ideário freiriano: a criticidade. É preciso aprofundar a análise dos conhecimentos construídos, possibilitando uma compreensão crítica da manifestação corporal na escola e fora dela. 
Rigorosidade também não é sinônimo da falta de alegria, de liberdade ou de criatividade. É o primeiro saber necessário à prática educativa apresentado por Freire (2010), esperado dos educadores, com o desvelamento da realidade por meio da reflexão crítica e amorosa constituída com os educados durante o processo educacional.

O que podemos perceber, sem sombra de dúvida, é a relevância das ideias [...] de Paulo Freire para o advento de práticas pedagógicas democráticas e críticas, avolumando a expressão de um currículo culturalmente orientado para o componente escolar. Nesse caminho, o professor assume um papel central, no sentido de reorientar o currículo, transformando-o em um documento transgressor de práticas tradicionais e hegemônicas, além de se reconhecer como o regente de processos educativos que contribuam para a construção da autonomia dos alunos, independentemente, das questões de classe, etnia, gênero, religião, sexismo etc. (MONTEIRO, 2018, p. 268).

\section{Reflexões momentâneas: indícios da Educação Física contra-hegemônica}

Em pesquisa realizada por Monteiro (2018), os professores partícipes sinalizaram a necessidade de uma mudança da postura pedagógica para que a concepção tradicional esportivista, biológica e elitista - da Educação Física seja suplantada e dê espaço à seleção e organização democrática das manifestações da cultura corporal. Pensar um novo paradigma para a área se mostra possível e inadiável, principalmente, nas redes públicas de Educação Básica.

A escola, ambiente multicultural, abarca alunos e alunas de diferentes comunidades, etnias, gênero, religião etc. e deve ser capaz de desempenhar sua função precípua, sem perder de vista a igualdade de direitos e o reconhecimento das diversas identidades culturais. Para isso, a dialogicidade entre os elementos que constituem a atuação docente deve ser diáfana, inquestionável e os sujeitos presentes neste cotidiano devem se empenhar em projetos pensados com a escola e não para a escola, sem isentar a instituição da responsabilidade que lhe compete.

O mesmo se dá para a Educação Física e seus professores, muitas vezes afastados das discussões pedagógicas da escola, outras vezes, em um processo de desinvestimento pedagógico (MACHADO et al., 2010). Pensar o cotidiano destes atores me aproxima dos conceitos de currículo praticado (FERRAÇO, 2008) e currículo pensadopraticado (OLIVEIRA, 2013), que jogam luz às práticas curriculares reais e combinam as orientações curriculares dos documentos oficiais aos saberes docentes e às possibilidades de atuação, oferecidas ou não, pelas unidades escolares. Ademais, constituem-se em políticas de currículo e colocam “[...] em suspeição as 
dicotomias clássicas não só da Educação, mas da Educação Física: teoria e prática, professor e aluno, conhecimentos científicos e conhecimentos do senso comum" (MONTEIRO, 2018, p. 217 218).

O protagonismo docente ganha força e relevância ao atribuir ao currículo e às práticas pedagógicas os valores democráticos, críticos e éticos presentes no arcabouço da teoria freiriana. Ghedin (2012), acautela que, muitas vezes, a maior dificuldade na implementação de currículos críticos e pós-críticos se dá, justamente, na ponta do trabalho educativo, na prática pedagógica dos professores. Nesse sentido, a conduta dos docentes se mostra antinômica, já que, ao mesmo tempo, refutam os currículos prescritos e pouco se dedicam às novas práticas, reproduzindo de forma descontextualizada as orientações dos documentos oficiais, reforçando as práticas discursivas e a desigualdade histórica instituídas no cotidiano escolar.

[...] a obra freiriana tem contribuições inquestionáveis e, ao mesmo tempo, pouco divulgadas. A educação contemporânea exige dos professores mais do que a técnica para ensinar ou o conhecimento científico, é preciso estar preparado para um projeto de sociedade multicultural, que anseia um indivíduo ético e autônomo. Assim sendo, os cursos de formação docente precisam oferecer aos futuros educadores mais do que os conteúdos específicos dos componentes curriculares; é preciso ensiná-los a ouvir, a perceber quais são os impactos sociais de sua prática pedagógica, a se comprometer com os aspectos ético, político e social do trabalho docente. Há que se ter coerência na ação educativa! (MONTEIRO; NISTA-PICCOLO, 2020, p. 124-125).

Daí a necessidade, premente, de mudanças de postura pedagógica, com os professores se comprometendo com um novo paradigma para a área: democrático, crítico, ético, amoroso, emancipatório, em todas as ações que envolvem a prática educacional. As estratégias devem

tratar das questões técnicas e estéticas das práticas corporais, mas sem perder de vista manifestações da cultura corporal que não sejam heteronormativas, brancas e eurocêntricas

O caminho a percorrer ainda é árduo, mas apenas assim será possível uma Educação Física escolar que, caso não esteja na escola, fará falta sim!

\section{Referências}

ANDREOLA, Balduíno Antonio. Carta-prefácio a Paulo Freire. In: FREIRE, Paulo. Pedagogia da indignação: cartas pedagógicas e outros escritos. São Paulo: UNESP, 2000. p. 10-14.

ARRUDA, Marina Patrício de et al. Alegria e amorosidade como estratégias de resistência para renovar a educação. Intermeio: revista do Programa de Pós-Graduação em Educação, Campo Grande, v. 25, n. 49, p. 243-259, jan./jun. 2019. 
CORAZZA, Sandra Mara. Planejamento de ensino como estratégia de política cultural. In: MOREIRA, Antonio Flavio Barbosa. Currículo: questões atuais. Campinas, Papirus, 1997. p. 103-143.

FERRAÇO, Carlos Eduardo (org.). Cotidiano escolar, formação de professores(as) e currículo. 2. ed. São Paulo: Cortez, 2008.

FRANÇOSO, Saulo; NEIRA, Marcos Garcia. Contribuições do legado freireano para o currículo da Educação Física. Revista Brasileira de Ciências do Esporte, Florianópolis, v. 36, n. 2, p. 531-546, abr./jun. 2014.

FREIRE, Paulo. Conscientização: teoria e prática da libertação: uma introdução ao pensamento de Paulo Freire. São Paulo: Cortez e Moraes, 1979.

FREIRE, Paulo. Educação como prática da liberdade. Rio de Janeiro: Paz e Terra, 1967.

FREIRE, Paulo. Educação e mudança. 12. ed. Rio de Janeiro: Paz e Terra, 1983a.

FREIRE, Paulo. A educação na cidade. 5 ed. São Paulo: Cortez, 2001.

FREIRE, Paulo. Pedagogia da autonomia: saberes necessários à prática educativa. São Paulo: Paz e Terra, 2010.

FREIRE, Paulo. Pedagogia da esperança: um reencontro com a pedagogia do oprimido. 22. ed. São Paulo: Paz e Terra, 2015.

FREIRE, Paulo. Pedagogia do oprimido. 62. ed. Rio de Janeiro: Paz e Terra, 2016.

FREIRE, Paulo. Professora sim, tia não: cartas a quem ousa ensinar. São Paulo: Olho d'Água, 1997.

FREIRE, Paulo. O sonho possível. In: BRANDÃO, Carlos Rodrigues (org.). O educador: vida e morte. 3. Ed. Rio de Janeiro: Edições Graal, 1983b. p. 89-101.

FREITAS, Ana Lúcia Souza de; COELHO, Carla Jeane Helfemsteller. Ética, educação e processos educativos escolares: um diálogo em construção. Ciência em Movimento - Educação e Direitos Humanos, Porto Alegre, v. 18, n. 37, p. 55-65, 2016.

GHEDIN, Evandro. Currículo, civilização e prática pedagógica. Revista e-curriculum, São Paulo, v. 10, n. 3, p. 71-87, dez. 2012.

GIROUX, Henry. Praticando estudos culturais nas faculdades de Educação. In: SILVA, Tomaz Tadeu da (org.). Alienígenas na sala de aula: uma introdução aos estudos culturais em educação. Petrópolis: Vozes, 1995. p. 85-103.

MACHADO, Thiago da Silva. et al. As práticas de desinvestimento pedagógico na Educação Física escolar. Movimento, Porto Alegre, v. 16, n. 2, p. 129-147, abr./jun. 2010.

MONTEIRO, Alessandra Andrea. Corporeidade e educação física: histórias que não se contam na escola. 2009. 165f. Dissertação (Mestrado em Educação Física) - Programa de Pós-Graduação em Educação Física, Universidade São Judas Tadeu, São Paulo, 2009.

MONTEIRO, Alessandra Andrea. Práticas Pedagógicas em educação física: diálogos com Paulo Freire. 2018. 316f. Tese (Doutorado em Educação) - Programa de Pós-Graduação em Educação, Universidade de Sorocaba, Sorocaba, 2018.

MONTEIRO, Alessandra Andrea; NISTA-PICCOLO, Vilma Lení. Diálogos com Paulo Freire no cotidiano da Educação Física Escolar. Curitiba: Editora CRV, 2020.

NEIRA, Marcos Garcia. O currículo de educação física e o posicionamento dos sujeitos. Revista Contemporânea de Educação, Rio de Janeiro, v. 11, n. 22, ago./dez. 2016. 
NEIRA, Marcos Garcia; NUNES, Mario Luiz Ferrari. Educação física, currículo e cultura. São Paulo: Phorte, 2009.

OLIVEIRA, Inês Barbosa de. Currículo e processos de aprendizagemensino: Políticaspráticas Educacionais Cotidianas. Currículo sem Fronteiras, Rio Grande do Sul, v. 13, n. 3, p.375-391, set./dez. 2013.

SÃO PAULO. Secretaria Municipal de Educação. Coordenadoria Pedagógica. Currículo da cidade: ensino fundamental: educação física. São Paulo: SME/COPED, 2017.

STRECK, Danilo Romeu; REDIN, Euclides; ZITKOSKI, Jaime José (Orgs.). Dicionário Paulo Freire. 3 ed. 1 reimp. Belo Horizonte: Autêntica, 2017.

TARDIF, Maurice. Saberes docentes e formação profissional. 12. ed. Petrópolis: Vozes, 2011.

TARDIF, Maurice; LESSARD, Claude. O trabalho docente: elementos para uma teoria da docência como profissão de interações humanas. 6. ed. Petrópolis: Vozes, 2011.

VELOZO, Emerson Luís. Cultura de movimento e identidade: a educação física na contemporaneidade. 2009. 157f. Tese (Doutorado em Educação Física) - Faculdade de Educação Física, Universidade Estadual de Campinas, Campinas, 2009. 